\title{
3B Yazıcının Kontrolünde Optimizasyon Algoritmalarının Performansı
}

\author{
Performance of Optimization Algorithms in the Control of 3D Printer
}

\author{
Aytaç ALTAN $^{1}$ (D), Ahmet PARLAK ${ }^{1}$ \\ ${ }^{I}$ Zonguldak Bülent Ecevit Üniversitesi, Elektrik Elektronik Mühendisliği Bölümü, 67100, Zonguldak, Türkiye
}

\begin{abstract}
$\ddot{\mathbf{O} z}$
Üç boyutlu (3B) biyo yazıcılar, rejeneratif tıp ve doku mühendisliği alanlarında özellikle kulak, burun ve yüz-çene protezlerinin biyo baskılarında yoğun şekilde kullanılmaktadırlar. Modelden modele farklılık gösteren baskı hataları yapay doku ve organların biyo-baskılarında sıklıkla görülmektedir. Modelin yüzeyinde meydana gelen hatalar yazdırılacak organın verimli kullanımına engel olmaktadır. Yapay doku ve organ biyo-baskısı sürecinde meydana gelen hataların en aza indirilebilmesi için 3B yazıcının kontrolcü performansının iyileştirilmesi gerekmektedir. Bu çalışmada, yapay doku ve organların biyo-baskıları için İyileştirilmiş Gri Kurt Optimizasyon (İGKO) tabanlı yeni bir uyarlanabilir PID kontrolcü geliştirilmiştir. Yerel minimumlardan kaçınmak için İGKO algoritması tercih edilmiştir. Önerilen algoritmanın yakınsama hızı PID kontrolcünün parametrelerinin hızlı ve doğru şekilde ayarlanabilmesine olanak sağlamaktadır. Geliştirilen İGKO tabanlı uyarlanabilir PID kontrolcünün performansı, performans metriklerinden biri olan zaman ağırlıklı karesel hatanın integrali (Integral of Time multiplied Squared Error-ITSE) yardımıyla ölçülmüştür. 3B yazıcı için önerilen kontrolcünün performans1, klasik PID ve Balina Optimizasyon Algoritması (BOA) tabanlı PID kontrolcülerin performans1 ile karşılaştırılmıştır. Elde edilen deneysel sonuçlardan, önerilen İGKO tabanlı uyarlanabilir PID kontrolcünün 3B yazıcının geçici tepkisini önemli ölçüde iyileştirdiği ve yazdırılan burun ve kulak gibi organlardaki yüzey hatalarını en aza indirdiği görülmektedir.
\end{abstract}

Anahtar Kelimeler: 3B yazıcı, Yapay doku ve organ, Geliştirilmiş gri kurt optimizasyon, Uyarlamalı kontrol, Burun ve kulak protezi.

\begin{abstract}
Three-dimensional (3D) bio printers are used extensively in regenerative medicine and tissue engineering, especially in bioprinting of ear, nose and face-chin prostheses. Printing defects that differ from model to model are frequently seen in the bio-printing of artificial tissue and organ. Defects occurring on the surface of the model prevent the efficient use of the organ to be printed. The controller performance of the 3D printer needs to be improved so that defects in the artificial organ and tissue bio-printing process can be minimized. In this study, a novel adaptive PID controller based on Improved Grey Wolf Optimization (IGWO) has been developed for bio-printing of artificial tissues and organs. The IGWO algorithm has been preferred to avoid local minima. The convergence speed of the proposed algorithm allows the parameters of the PID controller to be adjusted quickly and accurately. The performance of the developed IGWO based adaptive PID controller has been measured with the help of Integral of Time multiplied Squared Error (ITSE), one of the performance metrics. The performance of the proposed controller for the 3D printer has been compared to the classical PID and Whale Optimization Algorithm (WOA) based PID controllers's performance. From the experimental obtained results, it can be seen that the proposed IGWO based adaptive PID controller significantly improves the 3D printer's transient response and minimizes surface defects in the printed organs such as the nose and ear.
\end{abstract}

Keywords: 3D printer, Artificial tissue and organ, Improved grey wolf optimization, Adaptive control, Nose and ear prosthesis.

\section{GİRIS}

3B yazıcılar mühendislik ve sağlı alanları başta olmak üzere endüstriyel sanatlar, otomotiv gibi birçok alanda yaygın olarak kullanılmaktadırlar. Üç boyutlu bir modelin yazdırılarak madde haline getirilmesini sağlayan 3B yazıcılar son yıllarda rejeneratif tıp ve doku mühendisliği alanlarında özellikle kulak, burun, kemik ve yüz-çene protezlerinin biyo baskılarında yoğun şekilde kullanılmaktadırlar [1-3]. Yapay dokuların biyofabrikasyonu için hücre-biyomateryal etkileşimlerini optimize ederek doku hasarı gibi zorlukların üstesinden gelen rejeneratif tıp alanında kullanılan 3B yazıcıların kontrolü genellikle klasik PID ile gerçekleştirilmektedir. 3B yazıcının ortopedik cerrahide kullanılan basit geometri ve sert yapıya sahip protez kemik modelinin yazdırılmasında gösterdiği performans ile rejeneratif tıp alanında kullanılan iç içe geçmiş karmaşık geometri ve yumuşak yapıya sahip kulak ve burun gibi modellerin yazdırılmasında gösterdiği performans arasında büyük farklılıklar görülmektedir $[4,5]$. Hem sert hem de yumuşak dokuya sahip yüz-çene protezi gibi modellerin yazdırılmasında ise kontrolcü performansından kaynaklı yüzeysel baskı hataları ön plana çıkmaktadır. Bu doku ve organların biyo-baskılarında modelden modele değişen hataların en aza indirilmesi modelin etkin kullanımı açısından 
oldukça önemlidir [6]. Yazdırılan modelin referans modele göre yüksek hata oranına sahip olması, hastanın yazdırılan protez modelden kaynaklı başka problemlerle karşılaşmasına neden olabilir. $\mathrm{Bu}$ hata oranının en aza indirilebilmesi amacıyla bu çalışmada İyileştirilmiş Gri Kurt Optimizasyon (İGKO) algortiması tabanlı yeni bir uyarlanabilir PID kontrolcü geliştirilmiştir.

Yüz, çene, kafatası, boyun ve ağız bölgesi ile ilgili hastalık, travma, doku eksikliği ve estetik sorunların tanı ve tedavisi maksillofasiyel cerrahi olarak adlandırılmaktadır. Plastik cerrahi, estetik cerrahi, rekonstrüktif mikrocerrahi, ortognatik cerrahi, diş hekimliği ve kulak burun boğaz hekimliği maksillofasiyel cerrahinin ilgi alanları arasında yer almaktadır. Hastanın yüz bölgesinde, özellikle kulak, burun ve çene bölgesindeki kusurlar, hastanın duygusal bütünlüğünü, sosyal etkileşimini, benlik algısını ve yaşam kalitesini olumsuz yönde etkilemektedir. Maksillofasiyal kusurları olan hastaların yaşam kalitesi, cerrahi rekonstrüksiyon veya protez sağlandığında bile genellikle risk altındadır [69]. Travmatik burun ve kulak kusurları, özellikle toplumda gerçekleştirilen aktivitelerde özgüven, moral ve motivasyon kayıplarına neden olabilmektedir [10]. Burun ve kulağın yüz bölgesindeki konumu göz önünde bulundurulduğunda, bu organların kaybı veya bu organlarda oluşacak kusurlar hastanın fiziksel görünümünü olumsuz yönde etkileyeceğinden, cerrahi operasyonun mümkün olmadığg durumlarda giyilebilir protez burun veya kulağın kullanımı büyük önem taşımaktadır [11]. Ayrıca, aynalanacak mevcut bir parça olmadığında, geleneksel taş kalıplar kullanılarak üretilen protez burun ve kulağın hastaya uygulanmasında problemler yaşandığı bildirilmektedir [12]. Literatürde yapılan çalışmalarda, burun ve kulak kaybı olan hastalara uygun protez organların basılması için hastanın yüz bölgesindeki yumuşak ve sert doku ayrı ayrı segmentlere ayrılmaktadır. Protezin hastanın cilt rengine uyumlu olması, hastanın protezi etkin kullanabilmesi açısından önemli olduğu için hastanın cilt rengi bir spektrofotometre ile ölçülmektedir. Protez organı takmadan önce kulak veya burun kaybı olan hastaların görünümü sırasıyla Şekil 1 (a) ve Şekil 2 (a) 'da gösterilmektedir. Hastanın cilt tonuna uygun olarak 3B yazıcıda basılan kulak ve burun, yüz bölgesinde segmentlere ayrılan yumuşak doku ve sert doku ile bütünleştirilmektedir. [1, 11]. 3B yazıcıda ile yazdırılan ve hastanın yüz bölgesine monte edilen protez kulak ve burnun görünümü sırasıyla Şekil 1 (b) ve Şekil 2 (b) 'de gösterilmektedir.

Bu çalışmada, yapay doku ve organların biyo baskıları için 3B yazıcıda kullanılmak üzere yeni bir İGKO tabanlı uyarlanabilir PID kontrolcü geliştirilmiştir. Geliştirilen uyarlanabilir kontrolcünün parametreleri, IGKO algoritması kullanılarak ayarlanmaktadır. Ayrıca, protez organların yazdırılmasında, üretimden kaynaklanan hataların en aza indirilebilmesi için özel olarak tasarlanan ve üç farklı üretim malzemesini tek bir sistemde kullanabilen ekstruder sarkacının konum kontrolü de uyarlamalı olarak gerçekleştirilmektedir. Önerilen kontrolcü yaklaşımının performansı deneysel çalışmalarla doğrulanmaktadır.
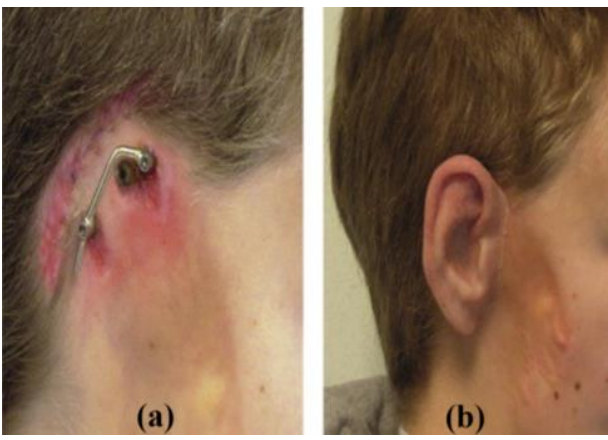

Şekil 1. Kulak kaybı olan (a) protezsiz (b) protezli hastanın görünümü [8]
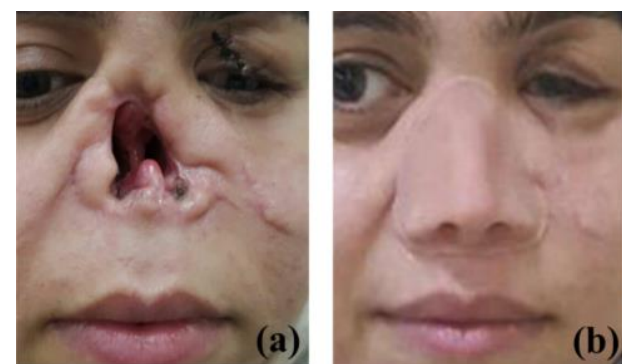

Şekil 2. Burun kaybı olan (a) protezsiz (b) protezli hastanın görünümü [10]

$\mathrm{Bu}$ çalışmanın geri kalanı şu şekilde organize edilmiştir: yapay doku ve organların biyo-baskıları için 3B yazıcı tasarımı Bölüm II'de anlatılmaktadır. Geliştirilen modele dayanak oluşturan Gri Kurt Optimizasyon (GKO) algoritması Bölüm III'te sunulmaktadır. İGKO tabanlı olarak geliştirilen uyarlanabilir PID kontrolcü algoritmasının 3B yazıcıya uygulanması Bölüm IV'te gösterilmektedir. Bölüm V'te deneysel sonuçlar verilmekte ve elde edilen sonuçlar tartışılmaktadır. Çalışmanın sonuçları Bölüm VI'da vurgulanmaktadır.

\section{DOKU VE ORGAN BIYYO BASKISI IÇIN 3B YAZICI TASARIMI}

Kartezyen, delta ve çekirdek $x y$ gibi farklı tasarımlarda üretilen $3 \mathrm{~B}$ yazıcılar genellikle $x y z$ kartezyen koordinat sistemine bağlı ekstruder, nozul ve 1sıtmalı yataktan oluşmaktadır [13]. Çalışmada kullanılan 3B yazıcının $x, y$ ve $z$ eksenlerinin hareketi aynı özelliğe sahip vidalı miller yardımı ile gerçekleştirilmektedir. Tasarlanan 3B yazıcının mekanik yapısı Şekil 3 'te gösterilmektedir. Tasarlanan 3B yazıcinın boyutları $600 \times 600 \times 700 \mathrm{~mm}$ 'dir. Yapay doku ve organların yazdırılması için kartezyen tip olarak tasarlanan 3B yazıcıda eksenler için dört adet ( $z$ ekseninde iki adet) ve filament sistemi için üç adet olmak üzere toplam yedi adet endüstriyel tip 
servo motor kullanılmaktadır. Ayrıca, ekstruder sarkaç için bir adet step motor kullanılmaktadır.

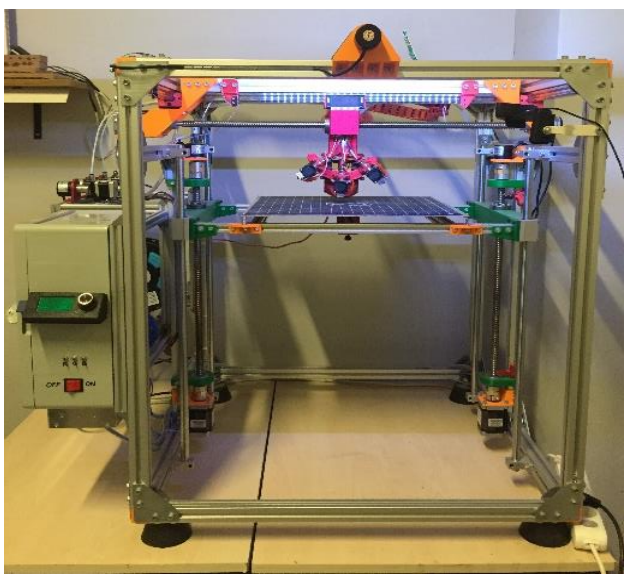

Şekil 3. Kulak ve burun gibi doku ve organların baskısı için tasarlanan 3B yazıcının mekanik yapısı

Tasarlanan 3B yazıcı $400 \times 400 \mathrm{~mm}$ 1sıtmalı yatağa ve $0.2 \mathrm{~mm}, 0.4 \mathrm{~mm}$ ve $0.6 \mathrm{~mm}$ çaplı nozullardan oluşan bir ekstruder sarkaş sistemine sahiptir. $\mathrm{Bu}$ çalışmada kullanılan 3B yazıcıyı diğer yazıcılardan ayıran en önemli özellik, ekstruder sarkaç sistemine sahip olmasıdır. Üç nozuldan oluşan ekstruder sarkaç sistemi Şekil 4'te gösterilmektedir. Yapay doku ve organların minimum hata ile basılabilmesi için 3B yazıcının eksen kontrolünün yanısıra ekstruder sarkaç sisteminin de etkin kontrolü oldukça önemlidir. Bu problemin üstesinden gelebilmek için bu çalışmada $3 \mathrm{~B}$ yazıcılardaki klasik PID kontrolcü algoritması yerine İGKO tabanlı uyarlanabilir PID kontrolcü algoritması geliştirilmekte, 3B yazıcı üzerinde bulunan ve Şekil 5 'te gösterilen kontrol kartı üzerine gömülmektedir. Geliştirilen kontrolcü algoritması aynı zamanda üç nozuldan oluşan ekstruder sarkaç sisteminin kontrolünü de gerçekleştirmektedir. Tasarlanan 3B yazıcı üç çeşit filamenti ekstruder sarkaç sistemi yardımıyla aynı anda kullanabilmektedir. $\mathrm{Bu}$ tür bir sistemin gereksinimi, modelin hastanın cilt rengindeki tonlamalara uygun olarak yazdirılabilmesine olanak sağlamasıdır. Ayrıca, model katmanlarında çeşitli tipte malzeme kullanımına imkân verilerek protez modelin yumuşak-sert doku uyumu gerçekleştirilebilmektedir.

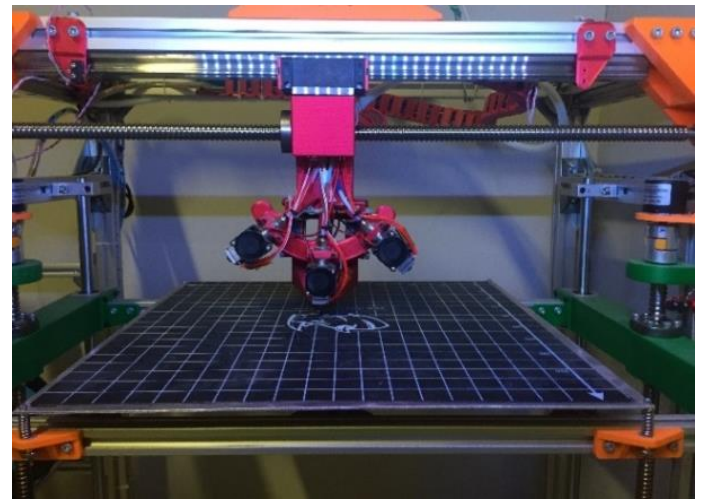

Şekil 4. Doku ve organ biyo-baskısı için tasarlanan 3B yazıcının ekstruder sarkaç sistemi

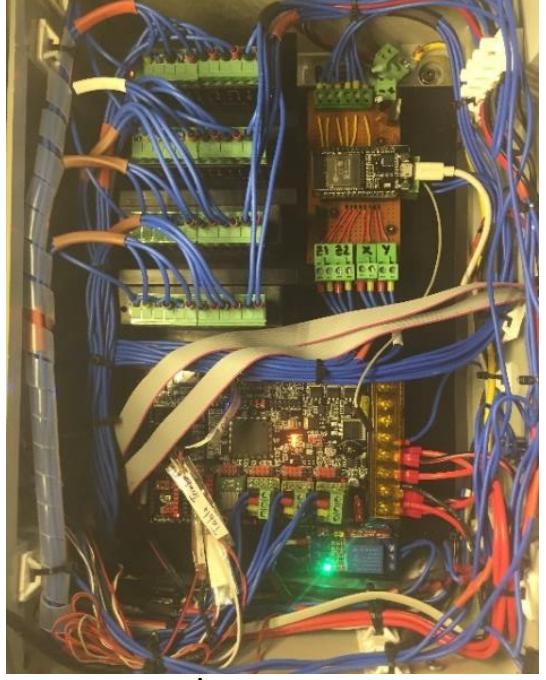

Şekil 5. Geliştirilen İGKO tabanlı uyarlanabilir PID kontrolcü algoritmasının gömülü olduğu kontrol kartı

\section{GRİ KURT OPTIMIZASYONU}

GKO, doğadaki gri kurtların avlanma davranışının ve sosyal liderliğinin simülasyonuna dayanan sürü zekâsı temelli evrimsel bir hesaplama yöntemi olan yeni ve etkili bir meta-sezgisel optimizasyon algoritmasıdır [14]. Gri kurtlardan esinlenen bu algoritmada gri kurdun liderliği ve avlanma mekanizmaları taklit edilir. Liderlik hiyerarşisini taklit etmek için alfa $(\alpha)$, beta $(\beta)$, delta $(\delta)$ ve omega $(\omega)$ olmak üzere dört tür gri kurt tanımlanmaktadır. GKO algoritmasının doğası $\omega$ kurtlar tarafindan takip edilirken $\alpha, \beta$ ve $\delta$ kurtları optimizasyon sürecine rehberlik etmektrdir. Gri kurt avının ana aşamaları:

- avı kovalamak, yaklaşmak ve takip etmek

- avın peşinde koşmak, taciz etmek ve etrafını sarmak

- sabit bekleme ve avına doğru saldırı.

Gri kurtların avlanma davranış aşamaları Şekil 6'da gösterilmektedir. Avın peşinden koşma, yaklaşma ve takip etme aşaması Şekil 6 (A)'da; avın peşinden koşma, taciz etme ve kuşatma aşamaları Şekil 6 (BD)'de; durağan bekleme ve avına doğru saldırı aşamaları Şekil 6 (E)'de gösterilmektedir.

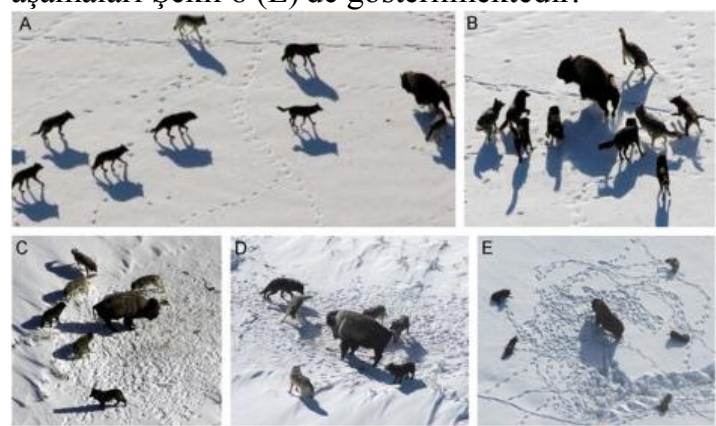

Şekil 6. Gri kurtların avlanma davranışı

Gri kurdun avlanma boyunca etrafı saran davranışı [14, 15]: 
$\vec{D}=\left|\vec{C} \cdot \overrightarrow{X_{P}}(t)-\vec{X}(t)\right|$

$\vec{X}(t+1)=\overrightarrow{X_{P}}(t)-\vec{A} \cdot \vec{D}$

ile modellenmektedir. Burada, $t$ mevcut yinelemeyi temsil etmektedir. $\vec{A}$ ve $\vec{C}$ katsayı vektörleridir. $\vec{X}(t)$ ve $\overrightarrow{X_{P}}(t)$, sirasiyla gri kurt ve avın konum vektörleridir. $\vec{A}$ ve $\vec{C}$ vektörleri,

$\vec{A}=2 \vec{a} \cdot \overrightarrow{r_{1}}-\vec{a}$

$\vec{C}=2 \cdot \overrightarrow{r_{2}}$

yardımıyla hesaplanmaktadır. Burada, $\overrightarrow{r_{1}}$ ve $\overrightarrow{r_{2}},[0,1]$ aralığında rastgele vektörlerdir. $\vec{a}$ bileşenleri iterasyon boyunca doğrusal olarak 2'den 0'a azaltılmaktadır.

Gri kurtlar, avın konumunu tanıma ve onu kuşatma yeteneğine sahiptirler. Gri kurtların avlanma davranışını matematiksel olarak simüle etmek için $\beta$ ve $\delta$ kurtların avın potansiyel konumu hakkında daha iyi bilgiye sahip olduğu varsayılarak $\alpha$ en iyi çözüm kabul edilmektedir. Bu süreç,

$\overrightarrow{D_{\alpha}}=\left|\overrightarrow{C_{1}} \cdot \overrightarrow{X_{\alpha}}-\vec{X}\right|$

$\overrightarrow{D_{\beta}}=\left|\overrightarrow{C_{2}} \cdot \overrightarrow{X_{\beta}}-\vec{X}\right|$

$\overrightarrow{D_{\delta}}=\left|\overrightarrow{C_{3}} \cdot \overrightarrow{X_{\delta}}-\vec{X}\right|$

$\overrightarrow{X_{1}}=\overrightarrow{X_{\alpha}}-\overrightarrow{A_{1}} \cdot\left(\overrightarrow{D_{\alpha}}\right)$

$\overrightarrow{X_{2}}=\overrightarrow{X_{\beta}}-\overrightarrow{A_{2}} \cdot\left(\overrightarrow{D_{\beta}}\right)$

$\overrightarrow{X_{3}}=\overrightarrow{X_{\delta}}-\overrightarrow{A_{3}} \cdot\left(\overrightarrow{D_{\delta}}\right)$

$\vec{X}(t+1)=\frac{\overrightarrow{X_{1}}+\overrightarrow{X_{2}}+\overrightarrow{X_{3}}}{3}$

ile tanımlanmaktadır. Burada, $t$ mevcut yinelemeyi ifade etmektedir. $\overrightarrow{A_{1}}, \overrightarrow{A_{2}}$ ve $\overrightarrow{A_{3}}$ rastgele vektörlerdir. $\overrightarrow{X_{\alpha}}, \overrightarrow{X_{\beta}}$ ve $\overrightarrow{X_{\delta}}$ vektörleri sirasiyla $\alpha, \beta$ ve $\delta$ kurtlarının konumların belirtmektedirler.

Avın hareketi durduğunda gri kurtlar bir saldırı ile avı bitirirler. Avına yaklaşan matematiksel model için $\vec{a}$ değeri azaltılır. O sırada, $\vec{A}$ 'nın dalgalanma aralığı da $\vec{a}$ tarafindan azaltılmaktadır. Bir arama ajanının bir sonraki konumu, mevcut konumu ile avın konumu arasındaki herhangi bir konum olabilir. Avların aramak için birbirlerinden ayrılan ve avına saldırmak için bir araya gelen gri kurtlar, çoğunlukla $\alpha, \beta$ ve $\delta$ kurtlarının konumuna göre arama yaparlar. Matematiksel model sapması için, arama ajanı avdan 1 'den büyük veya -1 'den küçük rastgele değerlerle ayrılmalıdır. GKO algoritması prosedürü aşă̆ıda tanımlanmıştır:

1: Gri kurt nüfusunu $X_{i}(i=1,2, \ldots, n)$ başlat

2: $a, A$ ve $C$ başlat

3: Her arama ajanının uygunluğunu hesapla

$X_{\alpha}$ : en iyi arama ajanı

$X_{\beta}$ : ikinci en iyi arama ajanı

$X_{\delta}$ : üçüncü en iyi arama ajanı

4: ( $t<$ maksimum yineleme sayısl) iken,

5: Her arama ajanı için

5.1: Denklem (11) tarafindan mevcut arama ajanının konumunu güncelle

6: $a, A$ ve $C$ güncelle

7: Her ajanın uygunluğunu hesapla

8: $X_{\alpha}, X_{\beta}$ ve $X_{\delta}$ güncelle

9: $t=t+1$

10: $X_{\alpha}$ değerini döndür.

$\mathrm{Bu}$ çalışmada yerel minimumlardan kaçınmak için GKO algoritması iyileştirilmiş ve kontrolcü parametre katsayıları belirlenmiştir. İyileştirilen algoritma Bölüm IV’te tanıtılmaktadır.

\section{3B YAZICI İÇİN GELIŞTIRILMIŞ GRİ KURT OPTIMIZASYON TABANLI PID KONTROLCÜ TASARIMI}

Yapay doku ve organların biyo-baskılarında kullanılan 3B yazıcıların kontrolü genellikle klasik PID kontrolcü algoritması ile gerçekleştirilmektedir. 3B yazıcı ile yazdırılan protezlerin imalat süreçlerinde meydana gelen hataların, özellikle yazdırılan protezlerin yüzeylerindeki hataların en aza indirilebilmesi için uyarlanabilir PID kontrolcü algoritması önerilmiştir [13]. Bu bölümde, yapay doku ve organların biyo-baskıları için tasarlanan 3B yazıcının geçici durum yanıtının iyileştirilebilmesi amaciyla önerilen İGKO tabanlı PID kontrolcü algoritması sunulmaktadır. Tasarlanan 3B yazıcı için geliştirilen İGKO tabanlı PID kontrolcünün blok yapısı Şekil 7'de gösterilmektedir. Şekil 7'de $\theta_{r}$ referans açısal konumu ifade etmektedir. $\theta_{e}$ açısal konum hatasını ve $u_{q}$ kontrolcü çıkış sinyalini belirtmektedir. $\theta$, kapalı döngü kontrol çıkışı olup gerçek açısal konumu göstermektedir. Geliştirilen İGKO tabanlı uyarlanabilir PID kontrolcünün performans1, en yaygin kullanılan performans ölçütlerinden biri olan zaman ağırlıklı karesel hatanın integrali (Integral of Time multiplied Squared ErrorITSE) yardımıyla ölçülmektedir. Denklem (12) ile ifade edilen bu performans ölçütü geliştirilen kontrolcünün parametrelerinin ayarlanmasinda kullanılmaktadır.

ITSE $=\int_{0}^{\infty} t\left[e(t)^{2}\right] d t$ 
Önerilen kontrolcü yapısında kullanılan İGKO algoritması prosedürü aşağıda tanımlanmıştır [17]:

Girişler : $n, d$ ve maksimum yineleme sayısı

Çıkış : Global optimum

1: Gri kurt nüfusunu $X_{i}(i=1,2, \ldots, n)$ başlat

2: $a, A$ ve $C$ başlat

3: Maksimum yineleme sayısı için Her arama ajanının uygunluğunu hesapla $X_{\alpha}$ : en iyi arama ajanı $X_{\beta}$ : ikinci en iyi arama ajanı $X_{\delta}$ : üçüncü en iyi arama ajanı

4: ( $t<$ maksimum yineleme sayısı) için,

5: Her arama ajanı için

5.1: Denklem (8-10) ile konum güncelle

5.2: Denklem (11) tarafindan mevcut arama ajanının konumunu güncelle

5.3: $R_{i}(t)=\left\|X_{i}(t)-X_{i}(t+1)\right\|$ güncelle

6: $d=1$ 'den $D$ için

6.1: Boyut öğrenmeye dayalı avlanma için

$X_{i-D H L, d}(t+1)=X_{i, d}(t)+\operatorname{rand} \times\left(X_{n, d}(t)-X_{r, d}(t)\right)$

7: $a, A$ ve $C$ güncelle

8: $X_{\alpha}, X_{\beta}$ ve $X_{\delta}$ güncelle

9: En iyi boyut öğrenmeye daylı konum ve mevcut ara ajan konumunu güncelle

10: Her ajanın uygunluğunu hesapla

11: Gri kurt nüfusunu güncelle

12: Global optimum değerini döndür.

\section{DENEYSEL SONUÇLAR}

Yapay doku ve organların biyo-baskıları için tasarlanan 3B yazıcının performansı, sırasıyla klasik PID ve geliştirilen İGKO tabanlı uyarlanabilir PID kontrolcü algoritmaları ile test edilmiştir. 3B yazıcının MATLAB ortamında oluşturulan matematiksel modeli üzerinde yapılan sistem yanıt analizine göre klasik PID kontrolcünün kazanç parametreleri ZieglerNichols yöntemi kullanılarak belirlenmiştir. Çalışmada önerilen kontrol algoritmasının optimizasyon süreci için popülasyon büyüklüğü ve toplam adım sayısı sirasiyla 40 ve 50 olarak belirlenmiştir. Çalışmadaki tüm kodlar MATLAB 2020 b ile derlenmiştir. Geliştirilen İGKO tabanlı uyarlanabilir PID kontrolcünün geçici durum yanıtı hem klasik PID kontrocünün hem de Balina Optimizasyon Algoritması (BOA) tabanlı PID kontrolcünün geçici durum yanıtı ile karşılaştırılmış ve sonuçlar Tablo 1'de sunulmuştur. Tablo 1'deki sonuçlar incelendiğinde, önerilen İGKO tabanlı uyarlanabilir PID kontrolcüsünün sistemin yanıtını önemli ölçüde iyileştirdiği doğrulanmıştır.

Tasarlanan 3B yazıcının performansı PID, BOA tabanlı PID ve İGKO tabanlı PID kontrolcü algoritmaları ile deneysel olarak test edilmiştir. Bu üç algoritma, sirayla tasarlanan 3B yazıcı üzerine gömülmüş ve protez kulak ve burun modelleri yazdırılmıştır. Klasik PID kontrolcüye sahip 3B yazıcı ile yazdırılan protez kulak ve burun modelleri sirasıyla
Şekil 8 ve Şekil 9'da verilmektedir. BOA tabanlı uyarlanabilir PID kontrolcüye ve önerilen İGKO tabanlı uyarlanabilir PID kontrolcüye sahip 3B yazıcı ile yazdırılan protez kulak ve burun modelleri sırasıyla Şekil 10 ve Şekil 11'de gösterilmektedir.

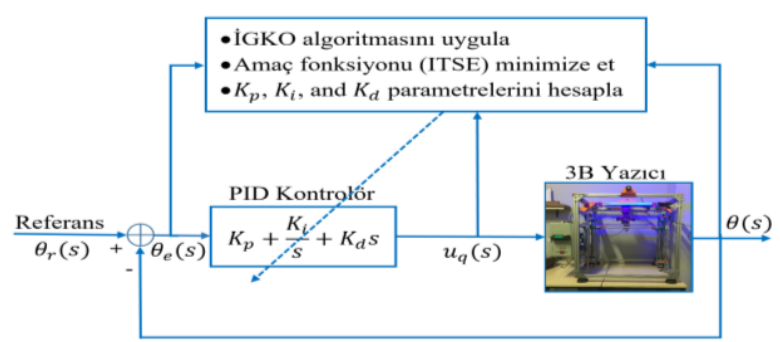

Şekil 7. Tasarlanan 3B yazıcı için geliştirilen İGKO tabanlı uyarlamalı PID kontrolcü blok yapısı

Tablo 1. 3B yazıcının geçici yanıt analizi sonuçları

\begin{tabular}{|c|c|c|c|c|}
\hline Kontrolcü & $\begin{array}{c}\text { Yükselme } \\
\text { zamanı } \\
(\mathbf{s})\end{array}$ & $\begin{array}{c}\text { Yerleşme } \\
\text { zamanı } \\
(\mathbf{2 \%}) \\
(\mathbf{s})\end{array}$ & $\begin{array}{c}\text { Maksimum } \\
\text { aşma } \\
(\mathbf{\%})\end{array}$ & $\begin{array}{c}\text { Tepe } \\
\text { zamanı } \\
(\mathbf{s})\end{array}$ \\
\hline PID [13] & $0.78 \times 10^{-3}$ & $0.97 \times 10^{-2}$ & 41.67 & $0.36 \times 10^{-2}$ \\
\hline $\begin{array}{c}\text { BOA-PID } \\
{[16]}\end{array}$ & $0.32 \times 10^{-6}$ & $0.08 \times 10^{-5}$ & No overshot & $0.14 \times 10^{-5}$ \\
\hline IGKO-PID & $0.49 \times 10^{-8}$ & $0.19 \times 10^{-7}$ & No overshot & $0.27 \times 10^{-7}$ \\
\hline
\end{tabular}

Tasarlanan 3B yazıcının performansı PID, BOA tabanlı PID ve İGKO tabanlı PID kontrolcü algoritmaları ile deneysel olarak test edilmiştir. $\mathrm{Bu}$ üç algoritma, sirayla tasarlanan 3B yazıcı üzerine gömülmüş ve protez kulak ve burun modelleri yazdırılmıştır. Klasik PID kontrolcüye sahip 3B yazıcı ile yazdirılan protez kulak ve burun modelleri sirasıyla Şekil 8 ve Şekil 9'da verilmektedir. BOA tabanlı uyarlanabilir PID kontrolcüye ve önerilen İGKO tabanlı uyarlanabilir PID kontrolcüye sahip 3B yazıcı ile yazdirılan protez kulak ve burun modelleri sirasıyla Şekil 10 ve Şekil 11'de gösterilmektedir.

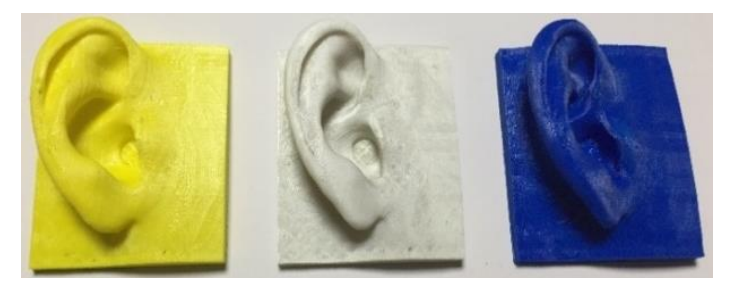

Şekil 8. Klasik PID kontrolcüye sahip 3B yazıcı ile basılan protez kulak modelleri [16]

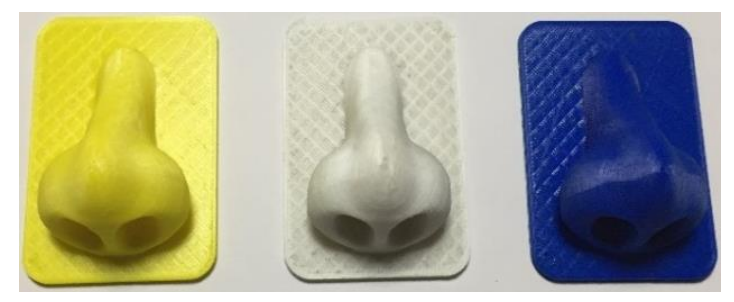

Şekil 9. Klasik PID kontrolcüye sahip 3B yazıcı ile basılan protez burun modelleri [16] 


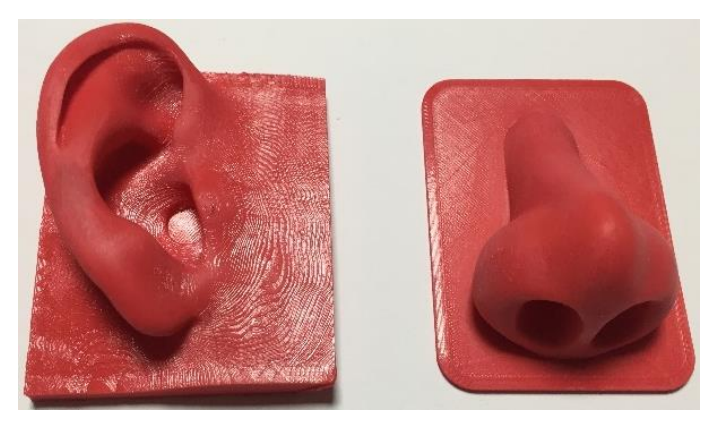

Şekil 10. BOA-PID kontrolcüye sahip 3B yazıcı ile basilan protez kulak ve burun modelleri [16]

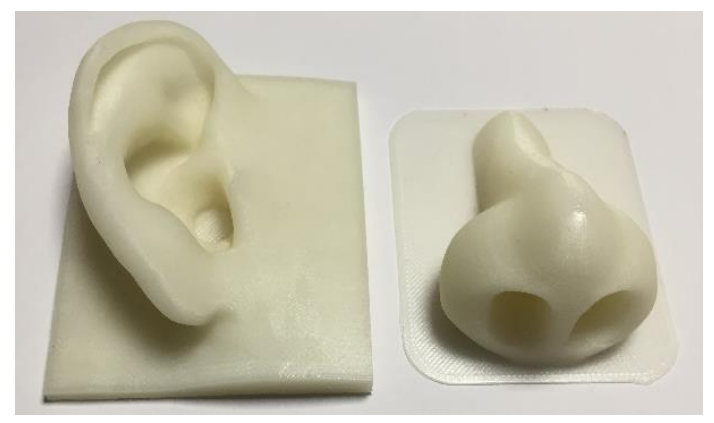

Şekil 10. İGKO-PID kontrolcüye sahip 3B yazıcı ile basilan protez kulak ve burun modelleri

Çalışmada önerilen optimizasyon algoritmasının performansı çalışma [16]'da kullanılan algoritma ile karşılaştırıldığında, İGKO algortimasının yakınsama hızının BOA'nın yakınsama hızına göre daha iyi olduğu, yerel minimumlardan kaçınabildiği ve global optimum başarımının daha yüksek olduğu deneysel olarak doğrulanmıştır.

Önerilen kontrolcü algoritması ve karşılaştırılan diğer kontrolcü algoritmaları ile yazdirılan yapay organlardaki deformasyon miktarları Pearson korelasyonu ile belirlenmiştir. $R$, ölçülen ve istenen değerler arasındaki doğrusal ilişkinin düzeyinin bir ölçümünü sağlar. $R$ değeri, hedefler ve çıktılar arasındaki ilişkinin bir göstergesi olarak tanımlanır. $R=1$ ise, hedefler ve çıtılar arasında tam bir doğrusal ilişki vardır. $R$ sıfıra yakınsa, hedefler ve çıktılar arasında doğrusal bir ilişki yoktur. $R$ değeri [18];

$R=\frac{\sum_{i=1}^{n}\left(x_{i}-\bar{x}\right)\left(y_{i}-\bar{y}\right)}{\sqrt{\sum_{i=1}^{n}\left(x_{i}-\bar{x}\right)^{2}} \sqrt{\sum_{i=1}^{n}\left(y_{i}-\bar{y}\right)^{2}}}$

ile elde edilir. Burada, $\bar{x}$ ve $\bar{y}$ sırasıyla ortalama hedef değerler ve ölçülen değerlerdir. Klasik PID kontrolcüye sahip 3B yazıcı ile basılan protez kulak ve burun modelleri için deformasyon oranları sırasıyla ortalama \% 19.76 ve \% 17.62'dir. BOA tabanlı PID kontrolcüye sahip 3B yazıcı [16] ile basılan protez kulak ve burun modelleri için deformasyon oranları sirasiyla $\% 0.673$ ve $\% 0.349$ 'dur. Önerilen İGKO tabanlı uyarlanabilir PID kontrolcü algoritmasına sahip 3B yazıcı ile basılan protez kulak ve burun modelleri için deformasyon oranları sırasıyla \% 0.024 ve $\% 0.013$ 'tür.

\section{SONUÇLAR}

$\mathrm{Bu}$ çalışmada, kulak ve burun gibi yapay doku ve organların biyo-baskıları için parametreleri metasezgisel optimizasyon algoritmalarından IGKO ile kestirilen yeni bir uyarlanabilir PID kontrolcü geliştirilmiştir. Geliştirilen kontrolcü algoritması özgün olarak tasarlanan 3B yazıcı üzerinde test edilmiştir. İGKO algoritması, en iyi PID kontrolcü parametrelerinin ayarlanması için ITSE performans kriterlerine göre adım adım çalıştırılmıştır. Deneysel çalışmalardan elde edilen sonuçlar, önerilen yaklaşımın PID kontrolcünün parametrelerini hızlı ve etkili bir şekilde hesapladığını göstermiştir. Tasarlanan 3B yazıcıda kulak ve burun protez modelleri yazdırılarak yazıcının performansı deneysel olarak test edilmiştir. Geliştirilen İGKO tabanlı uyarlamalı PID algoritması ile elde edilen sonuçlar literatürdeki BOA tabanlı uyarlamalı PID ve klasik PID kontrolcü sonuçları ile karşılaştırılmıştır. Tasarlanan 3B yazıcı ile birlikte önerilen İGKO tabanlı uyarlanabilir kontrolcünün protez kulak ve burun üretim sürecindeki hataları belirgin biçimde azalttığı gözlemlenmiştir. Özellikle protez doku ve organların iç içe geçmiş kompleks geometrilere sahip baskılarında önemli bir sorun olan yüzey hataları önerilen algoritma ile en aza indirilmiştir. Gelecek çalışmalarda canlı yapıların, doku ve organların oluşturulabilmesi için canlı hücrelerin minimum hata ile konumlandırılmasını sağlayacak yapay zekâ temelli algoritmalar tasarlanan 3B yazıcının kontrolünde kullanılacaktır. $\mathrm{Bu}$ sayede, canlı hücrelerin hassas konumlandırılmasıyla hedef doku veya organların oluşturulması esnasında meydana gelen yüzey alanı ve üretim kusurları en aza indirilebilecektir.

\section{TEŞEKKÜR}

$\mathrm{Bu}$ çalışma Zonguldak Bülent Ecevit Üniversitesi Bilimsel Araştırma Projeleri Birimi (BAP) tarafından 2020-75737790-01 numaralı proje kapsamında desteklenmiştir.

\section{KAYNAKLAR}

[1] Nuseir, A., Hatamleh, M. M. D., Alnazzawi, A., Al- Rabab'ah, M., Kamel, B., \& Jaradat, E., (2019). Direct 3D printing of flexible nasal prosthesis: optimized digital workflow from scan to fit. Journal of Prosthodontics, 28(1), 10-14.

[2] Zhong, N., \& Zhao, X., (2017). 3D printing for clinical application in otorhinolaryngology. European Archives of Oto-Rhino-Laryngology, 274(12), 4079-4089.

[3] Di Gesù, R., Acharya, A. P., Jacobs, I., \& Gottardi, R., (2020). 3D printing for tissue 
engineering in otolaryngology. Connective Tissue Research, 61(2), 117-136.

[4] Farook, T. H., Jamayet, N. B., Abdullah, J. Y., Rajion, Z. A., \& Alam, M. K., (2020). A systematic review of the computerized tools and digital techniques applied to fabricate nasal, auricular, orbital and ocular prostheses for facial defect rehabilitation. Journal of Stomatology, Oral and Maxillofacial Surgery, 121(3), 268277.

[5] Bauermeister, A. J., Zuriarrain, A., \& Newman, M. I., (2016). Three-dimensional printing in plastic and reconstructive surgery: a systematic review. Annals of Plastic Surgery, 77(5), 569576.

[6] Nemli, S.K., Aydin, C., Yilmaz, H., Bal, B.T., \& Arici, Y.K., (2013). Quality of life of patients with implant-retained maxillofacial prostheses: a prospective and retrospective study. The Journal of Prosthetic Dentistry, 109(1), 44-52.

[7] Irish, J., Sandhu, N., Simpson, C., Wood, R., Gilbert, R., Gullane, P., Brown, D., Goldstein, D., Devins, G., \& Barker, E., (2009). Quality of life in patients with maxillectomy prostheses. Head \& Neck: Journal for the Sciences and Specialties of the Head and Neck, 31(6), 813821.

[8] Levine, E., Degutis, L., Pruzinsky, T., Shin, J., \& Persing, J. A., (2005). Quality of life and facial trauma: psychological and body image effects. Annals of Plastic Surgery, 54(5), 502-510.

[9] Horlock, N., Vögelin, E., Bradbury, E. T., Grobbelaar, A. O., \& Gault, D. T., (2005). Psychosocial outcome of patients after ear reconstruction: a retrospective study of 62 patients. Annals of Plastic Surgery, 54(5), 517524.

[10] Hatamleh, M. M., Haylock, C., Watson, J., \& Watts, D. C., (2010). Maxillofacial prosthetic rehabilitation in the UK: a survey of maxillofacial prosthetists' and technologists' attitudes and opinions. International Journal of Oral and Maxillofacial Surgery, 39(12), 11861192.

[11] Watson, J., \& Hatamleh, M. M., (2014). Complete integration of technology for improved reproduction of auricular prostheses. The Journal of Prosthetic Dentistry, 111(5), 430-436.

[12] Hatamleh, M. M., \& Watson, J., (2013). Construction of an implant- retained auricular prosthesis with the aid of contemporary digital technologies: a clinical report. Journal of Prosthodontics: Implant, Esthetic and Reconstructive Dentistry, 22(2), 132-136.

[13] Altan, A., \& Hacığlu, R., (2018). The algorithm development and implementation for 3D printers based on adaptive PID controller. Journal of Polytechnic, 21(3), 559-564.

[14] Mirjalili, S., Mirjalili, S. M., \& Lewis, A., (2014). Grey wolf optimizer. Advances in Engineering Software, 69, 46-61.

[15] Wang, X., Zhao, H., Han, T., Zhou, H., \& Li, C., (2019). A grey wolf optimizer using Gaussian estimation of distribution and its application in the multi-UAV multi-target urban tracking problem. Applied Soft Computing, 78, 240-260.

[16] Altan, A., \& Parlak, A. (2020). Adaptive Control of a 3D Printer using Whale Optimization Algorithm for Bio-Printing of Artificial Tissues and Organs. IEEE Innovations in Intelligent Systems and Applications Conference, October, $1-5$.

[17] Nadimi-Shahraki, M. H., Taghian, S., \& Mirjalili, S., (2021). An improved grey wolf optimizer for solving engineering problems. Expert Systems with Applications, 166, 113917.

[18] Tan, P. N., Steinbach, M., \& Kumar, V., (2005). Introduction to Data Mining. Pearson Addison Wesley. 